\title{
Allocation of liquid food to larvae via trophallaxis in colonies of the fire ant, Solenopsis invicta
}

\author{
DEBY LEE CASSILL \& WALTER R. TSCHINKEL \\ Department of Biology, Florida State University
}

(Received 16 May 1994; initial acceptance 25 June 1994;

final acceptance 13 January 1995; $M S$. number: A7156R)

\begin{abstract}
In social insects, the size, caste and reproductive capacity of adults is determined in part by mutrition during larval development. Among ants, workers bring food to immobile larvae, giving workers potential control over larval nutrition, and making social feeding a potential mechanism of individual and colony ontogeny. During each regurgitation (trophallaxis), workers feed larvae the same, small increment of liquid food, regardless of larval attributes and conditions. Therefore, differences in the total volume of food ingested by larval resulted from differences in the rates of trophallaxis to them, not from differences in the durations of trophallaxis. The rates of worker-to-larva trophallaxis (feedings $/ \mathrm{h}$ ) were examined to investigate the mechanisms by which liquid food is allocated to larvae by workers. The rate of trophallaxis increased with larval food deprivation. The magnitude of this increase depended upon the larva's size. When larvae were food-deprived, larger larvae were fed at significantly higher rates than were smaller larvae (13 feedings for each $\mu$ l of larval volume). Once larvae of all sizes were satiated, workers fed them at similarly low rates. Regardless of size, larvae required about $8 \mathrm{~h}$ of feedings to reach satiation; that is, small larvae did not become sated any sooner than did medium or large larvae. Rates of trophallaxis were independent of: (1) the size or hunger of adjacent larvae, (2) rates, of larval encounter by workers (larvae were encountered hundreds of times per $h$ but were fed only tens of times); (3) larval location on the brood pile (top or bottom); and (4) larval body orientation (mouthparts up or down). These results provide the first quantitative evidence that an individual larval hunger cue directs the feeding of each larva, and that the strength of this cue, and therefore the feeding rate, varies with larval size and hunger.

1995 The Association for the Study of Animal Behaviour
\end{abstract}

The reproductive success of a wide variety of insects is determined to a large degree by nutrition during the larval period. Larval nutrition can affcet adult fccundity directly through increased reserves for egg production or indirectly through increased female body size. In social Hymenoptera, larval nutrition takes on special importance because it can influence the caste of the resulting adult (Wheeler 1994). Social feeding, in which adults feed immobile larvae, is a potential mechanism for regulating adult caste by means of nutritional switches that determine which of a small number of discrete developmental options a female larvae will follow (Wheeler 1986, 1990, 1994). The outcomes of these developmental options are the various female castes making up insect colonies: queens and workers

Correspondence: D. L. Cassill, Unit One, Department of Biology, Florida State University, Tallahassee, FL 32306-3050, U.S.A. (email: cassill@bio.fsu.edu). of single or multiple sizes. Thus, larval feeding may be a central, regulatory process in colony ontogeny.

Social feeding differs markedly among eusocial Hymenoptera. Wasp and bee larvae are reared individually in cells that are provisioned when food supplies become low (Pendral \& Plowright 1981; Huang \& Otis 1991; Hunt 1991). By contrast, ant larvae are reared communally in brood chambers, creating potential difficulties in assessing individual larval needs. The ability of ant workers to rear larvae successfully under such potentially confusing conditions has not been widely appreciated or investigated (Hölldobler \& Wilson 1990).

Recent studies have revealed fairly complex organization of ant brood by developmental stages within the communal brood chamber. Workers sort brood, maintaining eggs and firstinstar larvae separate from older larval instars within the same brood chamber, while keeping 
pupae in different (drier) brood chambers (Carlin 1988; Vander Meer \& Morel 1988; Deneubourg et al. 1991; Franks \& Sendova-Franks 1992). Workers deliver proteinaceous food primarily to larvae and queens and sugars primarily to other workers (Brian 1956; O'Neal \& Markin 1973; Abbott 1978; Petralia \& Vinson 1978; Howard \& Tschinkel 1980, 1981a, b; Sorensen et al. 1980; Sorensen \& Vinson 1981; Wheeler 1994) suggesting some mechanism by which larvae communicate their nutritional requirements, directly or indirectly, to workers. Communication between larva and worker may be two-way, because larvae appear to provide workers with a source of ingestable protein via glandular secretions or regurgitates (Markin 1970; Sorensen et al. 1983).

In $S$. invicta, most successful foragers return to the nest with fluid-filled crops rather than with solid food carried in the mandibles (Tennant \& Porter 1991). A substantial fraction of this liquid may be fed to larvae via trophallaxis. Yet little is known of the mechanisms, patterns and initiating circumstances of worker-to-larva trophallaxis. Food may be stochastically allocated to larvae, coupling the chance availability of food (Howard \& Tschinkel 1981a; Sutcliffe \& Plowright 1988) with the random encounter of larvae (Franks \& Sendova-Franks 1992; Hatcher et al. 1992). Trophallaxis may be controlled by colony-wide hunger (Brian \& Abbott 1977; Howard \& Tschinkel 1980; Sorensen et al. 1985), by worker hunger (Wallis 1962), or by individual larval hunger. Behavioural hunger as an individual cue was suggested by LeMasne (1953) and O'Neal \& Markin (1973); a chemical hunger cue was suggested by Wilson (1971) and Hölldober (1978). To date, there is no quantitative evidence for either type of larval hunger cue.

Experimental studies on larval hunger have yielded varied results. Among replicates within the same experiment, food-deprived larvae were sometimes fed more often, sometimes less often, or sometimes the same as satiated larvae (Myrmica rubra: Brian 1957; Brian \& Abbott 1977; S. invicta: Sorensen et al. 1985) suggesting that the amount of food delivered to larvae depended on factors other than a larva's hunger. Larval size may also be an important trait in the allocation of food to them. In M. rubra, Brian (1957) found that large larvae were fed more often than small larvae. In S. invicta, O'Neal \& Markin (1973) found that small larvae were fed via trophallaxis more often than large larvae. Later, in $M$. rubra and Lasius niger, respectively, Brian (1986) and Lenoir (1981) found that small larvae were fed more often than large larvae in the queen's presence, but the opposite occurred in the queen's absence.

We have shown that the duration of workerlarval trophallaxis was brief and nearly constant $(\bar{X} \pm \mathrm{SD}=11 \pm 2 \mathrm{~s})$, regardless of differences in larval size (within the fourth instar) or hunger (unpublished data). Because the size of boluses and the rate at which they were swallowed was also constant (regardless of larval size), the volume of food ingested by larvae during each trophallactic event was constant and very small. Therefore, simply counting the total number of larval feedings per unit time (rate of trophallaxis) was an accurate measure of the total volume of food ingested by each larva. Because of the small amount fed during each trophallactic event, hundreds of feedings are required to bring a larva to satiation.

In this study, we investigated the effects of larval attributes and conditions (size, fooddeprivation, body orientation and location in the brood pile) on the rate at which fourth-instar larvae were fed by workers. Only fourth-instar larvae were tested because $80-90 \%$ of growth from egg to adult takes place during this instar (Petralia \& Vinson 1979). Our findings revealed that the larva was not, after all, a 'sluggish, legless maggot' (Wheeler 1918) passively receiving food at the whim or fancy of worker decisions. Instead, each larva procured feedings from workers at rates most likely regulated by its metabolism and growth.

\section{METHODS}

\section{Stock Colonies and Artificial Nests}

Monogyne $S$. invicta colonies were reared in the laboratory from newly mated queens collected in Tallahassee, Florida, during the springs of 19881990. Laboratory rearing methods were similar to those described by Banks et al. (1981). Colonies were maintained at $28^{\circ} \mathrm{C}$ in constant light.

Plaster observation nests $(10 \times 14 \times 2 \mathrm{~cm}$ with a $0 \cdot 3$-cm-high rim around the top edge to form a brood chamber) were covered with a plate of glass through which the ants were videotaped. During experiments, plaster nests were kept damp because 
workers did not feed larvae in dry nests (unpublished data). Condensation sometimes formed on the glass cover of the saturated nest but caused only minor blurring of the recorded image.

\section{Manipulating Larval Factors}

\section{Food deprivation}

Larvae have a nearly transparent body wall through which the colour of the food they have ingested can be seen. We used food dyes as markers to distinguish larvae subjected experimentally to different durations of food deprivation (usually 12, 24 or $48 \mathrm{~h}$ ). Food consisted of artificial aqueous solutions of distilled water, $6 \%$ (w/v) Casamino Acids powder (DIFCO Laboratories; Howard \& Tschinkel 1981a), 33\% (v/v) corn syrup (Karo) and $0.2 \%$ (w/v) over-thccounter food dye (French's). The addition of food dyes to this solution had no effect on the percent of larvae fed (unpublished data).

Size

We sifted fourth-instar larvae into four size categories using standard testing sieves (Porter \& Tschinkel 1985b). Mesh sizes upon which larvae were collected (i.e. did not fall through) were: no. 35 for small, no. 30 for medium, no. 25 for large and no. 20 for extra-large larvae. We calculated larval size by sampling 20 larvae from each size class and measuring the length and width of each with an ocular micrometer. We then used these dimensions to calculate their volume or surface area. We approximated larval shape as a prolate spheroid to calculate their size using the following equations: volume $=4 / 3 \pi a b^{2}$; surface area $=2 \pi$ $b^{2}+2 \pi a b / e \sin ^{-1 e}$, where $a$ equals major axis or length $/ 2, b$ equals minor axis or width $/ 2$, and $e$ is eccentricity (Hodgman et al. 1956). Even with sieving, larvae varied by size between experiments. Therefore, we measured larval dimensions from the monitor and calibrated these to actual larval size for each replicate of the experiments in which size was a factor.

\section{Location in the brood pile}

Inside the brood chambers of experimental nests, larvae were often piled two and three deep. Larvae whose bodies were more than half covered by adjacent larvae were labelled 'bottom', others were labelled 'top'. As a rule, larvae were piled so loosely that workers had easy access to them at all times.

\section{Orientation}

Within the brood pile, larvae lie with mouthparts facing up, down or sideways. Larvae lying primarily on their dorsal surface with mouthparts visible to the camera were labelled 'up'; those lying on their ventral surface with mouthparts oriented away from the camera were labelled 'down'.

\section{Procedures}

\section{Experimental nest set-up}

We aspirated larvae from several stock colonies, combined them and placed them in a temporary holding nest with about 100 workers to groom them for the designated food-deprivation period. Because fire ant workers feed kin or non-kin larvae at the same rate (unpublished data), combining larvae from several source colonies was an acceptable practice. If more than one fooddeprivation period was required for an experiment, we fed larvae solutions (via workers) made with different-coloured food dyes prior to food deprivation. Thus, we could distinguish larvac of different starvation regimes from one another by colour even if they were present in the same nest.

We aspirated workers from a source colony's arena and brood chamber. One gram of workers (about 2000 individuals) was placed into each nest. Food was withheld $48 \mathrm{~h}$ prior to videotaping. This allowed time for the worker crop to empty itself of any liquid food it might contain (unpublished data). We placed larvae of specified size or food deprivation periods into the nest with workers (an invasive event) about $1 \mathrm{~h} \mathrm{before}$ videotaping began, thus allowing workers to recover from the disruption of adding the larvae. In pilot experiments, a mean lapsed time of 15-20 min occurred between food placement near the nest (a non-invasive event) and the first larval feeding. Therefore, we introduced food $30 \mathrm{~min}$ after adding larvae and $30 \mathrm{~min}$ before videotaping.

Larvae subjected to different treatments were sometimes recombined and tested together in one nest or they were kept apart and tested in separate nests. All experiments were replicated two to six 
times, using a different source colony for each relicate. The number of replicates reported in Methods is therefore the number of source colonies used.

\section{Data collection and videotaping technology}

Videotaping equipment consisted of a Sony colour video-camera (WV D5100) with lens (Taylor, Taylor \& Hobson, LTD, 2 in, F/1.4) and 1-6-cm extension tubes providing $20-40 \times \mathrm{mag}$ nification on the TV monitor, a JVC video cassette recorder (HR-D600U), a Sony Trinitron colour monitor and fibre optic lights. On tape, the camera's field of view at $20-40 \times$ power captured 50-100 larvae out of the thousands placed in each treatment group. These comprised the sample group for each experimental nest. From these videotapes, we collected feeding data for individual larvae as follows. (1) We placed the videotape on pause and selected a larva for analysis by marking the monitor screen. (2) We recorded information about that larva (i.e. its size, fooddeprivation state, location and orientation). (3) We started both the videotape and a computer event recorder simultaneously. We recorded the beginning and end of each feeding to that larva for the entire observation period (usually $1 \mathrm{~h}$ ). (4) We rewound the tape, reset the event recorder, marked a second larva and repeated the procedure until a sufficient sample of larvae had been obtained. For video-recordings of less than $1 \mathrm{~h}$, we prorated larval fecding rates to $1 \mathrm{~h}$ to facilitate comparisons between experiments (larval feeding rates remained constant during the first hour for a given larval size or food-deprivation state; unpublished data).

\section{Data and Data Reliability}

\section{Variables}

Three dependent variables were recorded for each larva during experiments: (1) the rate of trophallaxis (number of workers/h feeding a larva), (2) the rate of encounter (number of workers/h antennating a larva), and (3) the rate of assessment (number of workers/ $h$ giving a larva a single lick).

\section{Reliability}

We could always verify that ingestion occurred when a worker offered food to a larva by the sight of coloured boluses moving down the larval stomodaeum and by the accumulation of food dye in the larval midgut. Of the nearly 15000 tro. phallactic events that we quantified during $900 \mathrm{~h}$ of videotaping 1500 larvae, only once did a worker align with a larva without subsequent ingestion by the larva (probably a prepupa).

We counted trophallactic feedings while the videotapes were on the fast-forward mode (five times real time) to expedite data collection. The precision of collecting data on the fast-forward mode was estimated with seven repetitions of feedings to one larva over a 20 -min period. The number of feedings (27) was identical in all but one repetition (in that one, 26 feedings were recorded).

We determined the reliability of encounter data by twice counting the number of workers that antennated each of 12 larvae within a $30-\mathrm{min}$ period. The mean number of encounters differed by $3.4 \%(151 \cdot 2$ versus $156 \cdot 6)$.

A lick was identified by a single rapid head-bob with glossae extended. Because of its singularity and brevity, this behaviour appeared to be part of the worker's assessment routine rather than a grooming behaviour. We determined reliability as for encounter data. The mean number of licks differed by $2 \cdot 9 \%$ ( $44 \cdot 3$ versus $45 \cdot 6$ ).

\section{Experiment 1: Larval Food-deprivation, Size and Location versus Rates of Trophallaxis, Contact and Assessment}

We sifted larvae into four size classes, then halved each size class and exposed each half to one of two food-deprivation periods, either $0 \mathrm{~h}$ (dyed green) or 48-h food-deprivation (dyed red). After we established food-deprivation states, we mixed together an equal number of larvae from each size class and from each food-deprived state (totalling $1 \mathrm{~g}$ by live weight or $\sim 2000$ larvae by number), and placed them in an experimental nest with $3 \mathrm{~g}$ workers (pre-starved for $48 \mathrm{~h}$ ). We recorded the initial location of each larva even if it was later moved by a worker to the opposite location (top to bottom or vice versa). We videotaped two replicates, each for $30 \mathrm{~min}$, drawing workers for each replicate from a different source colony.

Initially, combining larvae of different sizes and food-deprivation states into one experimental chamber was viewed as violating the assumption 
of sampling independence. However, experiments 4 and 5 (described below) revealed that workerto-larva trophallaxis occurred independently of the conditions of adjacent larvae, allowing us to analyse and interpret data from this experiment without qualification.

We analysed data from this experiment by regression with indicator variables (Montgomery \& Peck 1982) from Minitab for PCs (Ryan et al. 1985). This analysis provided an overall analysis of variance (ANOVA) of differences between the categorical treatments, a Student's $t$-test of differences between paired treatments and an analysis of regression slopes with larval size as the independent variable. We determined the relationship of feeding rates to encounter or assessment rates with simple regression from Minitab. We removed outliers greater than $3 \mathrm{SD}$ and reanalysed the data. Analysis of residuals showed data met the assumptions of normality and homogeneity.

To determine whether temporal patterns (random, uniform or clustered) of larval contact by workers affected the temporal patterns of larval trophallaxis, we recorded intervals between contacts and between feedings and analysed them using the coefficient of variation statistic (COV; Zar 1974). Confidence intervals for randomness were calculated using Monte Carlo methods for each larva's pattern of feeding.

\section{Experiments 2 and 3: Larval Size}

Two additional experiments provided a more precise description of the effect of larval size on rates of trophallaxis. We starved larvae $(48 \mathrm{~h})$, sifted them into four size classes with about 250 larvae in each class and placed them with $1 \mathrm{~g}$ of workers. In cxperiment 2, wc mixed larvac from the four size classes together in one nest with workers from one source colony; thus, adjacent larvae were of different sizes. In experiment 3 , we tested larvae from the four size classes in separate nests, fragmenting workers from a single source colony into the four nests, one for each larval size. Thus, within each nest, adjacent larvae were of similar size. We made four replicates (four source colonies) for each experiment, videotaping each nest for $1 \mathrm{~h}$.

In experiment 2, the worker:larva ratio was 1.5:1 (we combined four larval size classes for a total of $\sim 1000$ larvae in the experimental nest), whereas in experiment 3 , the worker:larva ratio was 6:1 (we tested each larval size class of $\sim 250$ larvae in a separate nest). This difference in worker:larva ratios between experiments introduced a possible confounding variable. Fortunately for the interpretation of these experiments, worker:larva ratios ranging from $1: 1$ to 16:1 had no effect on the rate of larval feeding (unpublished data).

We used regression with indicator variables (see experiment 1) to analyse feeding rates by larval size, a $t$-test for regression (Zar 1974) to determine differences in regression slopes between experiments, and simple regression to determine the slope of feedings with larval size on the combined data from experiments 1-3.

\section{Experiment 4: Ratios of Sated and Food-deprived Larvae}

In experiment 1 , the ratio of satiated:fooddeprived larvae was 1:1. This experiment tested ratios greater than or less than 1:1. Would workers feed a few hungry larvae among many satiated larvae? Would they fail to feed a few satiated larvae among many hungry larvae? We tested larvae of two food-deprivation states $(0$ or $48 \mathrm{~h}$, using green and red food dyes to differentiate the states) and combined them into one of four different ratios: $100 \%$ food-deprived $+0 \%$ sated (control); $30 \%$ food-deprived $+70 \%$ sated; $5 \%$ food-deprived $+95 \%$ sated; $0 \%$ fooddeprived $+100 \%$ sated (control). Each treatment contained a total of $1 \mathrm{~g}$ of large larvae (e.g. $0.7 \mathrm{~g}$ satiated larvae plus $0.3 \mathrm{~g}$ food-deprived larvae) with $2 \mathrm{~g}$ of workers. We obtained workers for each of six replicates from six different source colonies and videotaped each treatment for each replicate for $30 \mathrm{~min}$. We analysed data as differences using ANOVA and $t$-tests from Minitab's regression with indicator variables (see experiment 1).

\section{Experiment 5: Other Larval and Worker Food-deprivation Periods}

In previous experiments, we tested either 0 -h or 48-h food-deprivation states for larvae and a 48-h food-deprivation state for workers. In this experiment, we tested the effects of other fooddeprivation periods for larvae and for workers on larval feeding rates. We food-deprived larvae for 0 (satiated), 12 or $24 \mathrm{~h}$ (using green, red and yellow 
food dyes to mark treament differences), then paired larvae by food-deprivation periods in all three possible combinations ( 0 and 12,0 and 24 , 12 and $24 \mathrm{~h}$ ). Each source colony yielded six nests; $1 \mathrm{~g}$ of workers in three of these nests (each containing $0.5 \mathrm{~g}$ paired larvae) were food-deprived for $24 \mathrm{~h}$ and $1 \mathrm{~g}$ of workers for the other three nests (each containing $0.5 \mathrm{~g}$ paired larvae) were fooddeprived for $92 \mathrm{~h}$. We videotaped two replicates (two source colonies), $1 \mathrm{~h}$ for each nest, then analysed these data as differences using ANOVA and $t$-tests from Minitabs' regression with indicator variables (see experiment 1 ).

\section{Experiment 6: Larval Feeding during 12 Hours}

This experiment defined the changes in the rate of feeding during a $12-\mathrm{h}$ observation period. We food-deprived larvae for $12 \mathrm{~h}$, sifted them into three size classes (each size class containing the same number of larvae), combined the size classes (totalling approximately $1 \mathrm{~g}$ ) and placed them with $2 \mathrm{~g}$ of workers. We videotaped each of four replicates (four source colonies) for $12 \mathrm{~h}$ in situ, while supplying food ad libitum. We analysed larval feeding rates as a simple regression with time as the independent variable, and differences in regression slopes between larval size classes using $t$-tests for regression (Zar 1974). We regressed the data recorded during the first $1-8 \mathrm{~h}$ separately from data recorded during the next 9-12 h.

We determined the proportion of the brood pile covered by workers over $12 \mathrm{~h}$ of videotaping by first drawing a grid onto the monitor. The grid was sized so that each cell could contain one 'large' larva of approximately $1 \mu$ l in actual volume (but magnified many timcs). We counted the number of cells containing at least one larva and the number of cells that contained both larvae and workers (e.g. 20 cells contained larvae; of those, 17 cells also contained workers). We recorded counts by pausing the videotape at random times (random numbers table: Byrkit 1980), and analysed these data as proportions regressed against time.

\section{Experiment 7: Larval Orientation}

We food-deprived ( $48 \mathrm{~h}$ ) $1 \mathrm{~g}$ of larvae of mixed sizes, then placed them with $1 \mathrm{~g}$ of workers (food-deprived for $48 \mathrm{~h}$ ) in an experimental nest with a brood chamber $4 \mathrm{~mm}$ deep. This deeper chamber allowed workers to pile larvae as might occur in natural nests. Two hours after we introduced food into the arena near the nest, we removed the glass plate and immediately dripped ether directly onto the brood pile to immobilize the workers. We placed the nest in a refrigerator at $4^{\circ} \mathrm{C}$ to maintain worker immobility. Later, we removed inert workers with minimum disturbance to larval positions within the brood pile and recorded larval size and orientation. We made six replicates (six source colonies) and analysed 1812 larvae. In addition to this experiment, we determined the rate of feeding to larvae of different orientation by placing $0.5 \mathrm{~g}$ of large, 12 -h food-deprived larvae with $1 \mathrm{~g}$ of workers. We replicated this experiment four times (four source colonies), videotaping each for $1 \mathrm{~h}$, and analysed these data with ANOVA.

\section{RESULTS}

\section{Description of Trophallaxis}

While moving about the brood pile, workers bobbed and swept their extended antennae over the larval body in short rapid vertical or hori. zontal strokes and gave an occasional brief single lick with the glossae. To initiate feeding, a worker moved to the larva's mouth parts, licked them once or twice then aligned herself along the antero-posterior axis of the larva (Fig. 1). The worker opened her mandibles and extended hes labium with the tip of the glossae pressed against or possibly into the larva's hyper-extended mouth. Larval ingestion began immediately after the worker regurgitated a film of fluid onto her glossae. For the duration of trophallaxis, the worker remained nearly motionless with man. dibles open and antennal tips positioned very near the larval mouthparts. Worker alignmen and immobility, which is quite unlike that of grooming in which the worker head-bobs repear edly as she moves over the larval cuticle, weri the signature postures for identifying trophal. lactic events. Antennae would begin to sweep just before the worker terminated feeding. The worker retracted her glossae and labium, often with a slight jerk, immediately prior to moving away from the larva. 


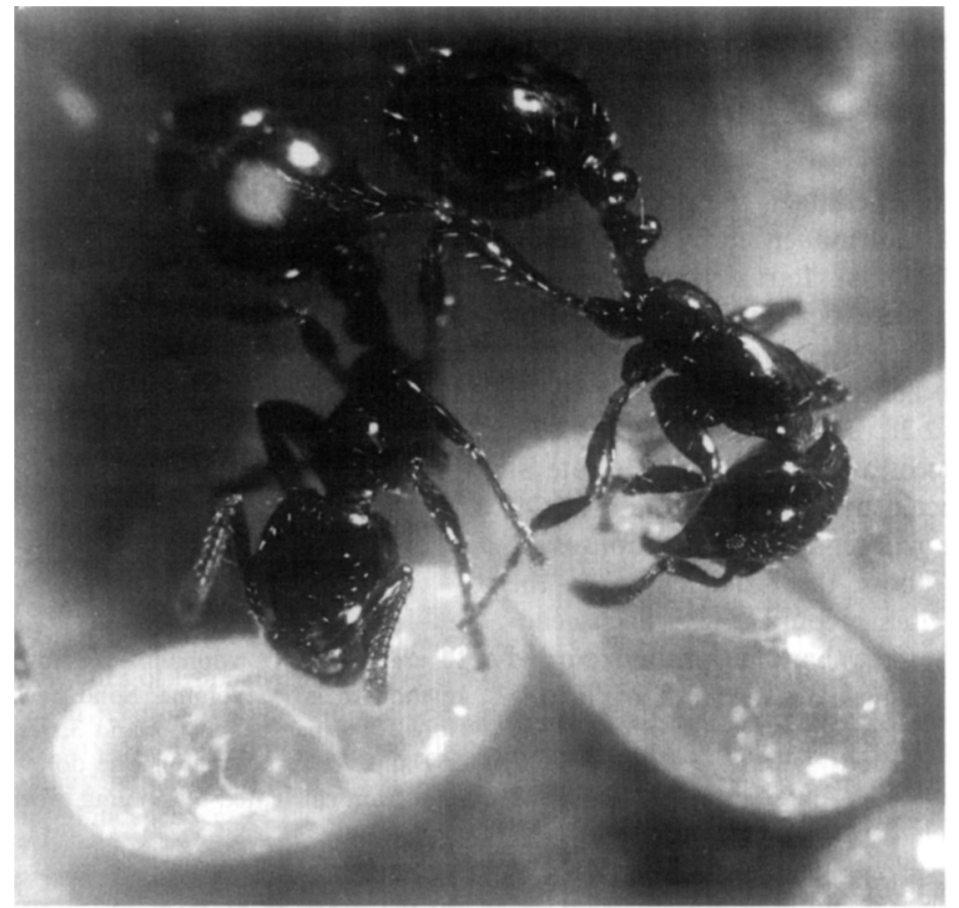

Figure 1. Typical alignment during worker-to-larva trophallaxis is the antero-posterior orientation shown in the worker-larva pair on the right. Less often, workers align in an antero-anterior orientation to larvae. Atypically, workers align at $90^{\circ}$ to the larva during trophallaxis, as shown in the worker-larva pair on the left.

\section{Experiment 1: Larval Food-deprivation, Size and Location versus Rates of Trophallaxis, Contact and Assessment}

\section{Rate of trophallaxis}

Food-deprived larvae were fed at significantly higher rates than were satiated larvae $(t=7.88$; $P<0.001)$. Larval size interacted with larval fooddeprivation: when larvae were food-deprived, larger larvae were fed at significantly higher rates than smaller larvae $\left(F_{3,43}=44.26, P<0.0001\right.$; Fig. 2); but when larvae were satiated, larval size (volume) had no effect on the rate of trophallaxis $\left(F_{3,32}=0.93\right.$, Ns $)$. Larvae located atop the brood pile were fed at the same rate as were larvae located at the bottom of the brood pile $(t=0.65$, Ns).

\section{Rate of contact}

The rate with which workers contacted (antennated) larvae was not affected by larval fooddeprivation $(t=1 \cdot 24$, Ns) nor by larval size (surface

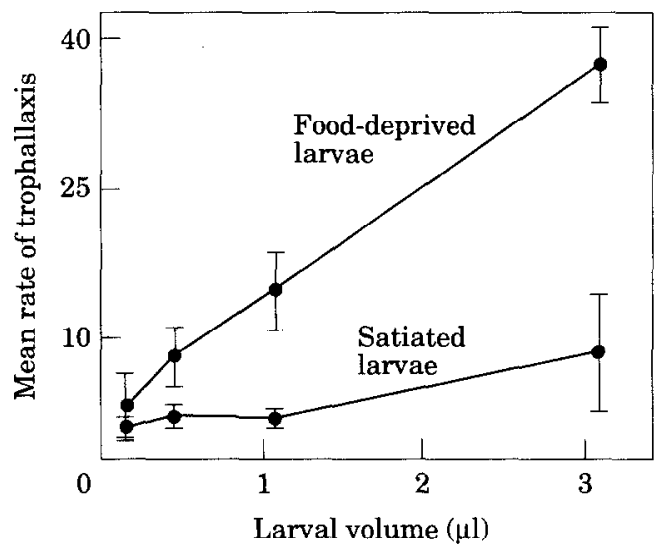

Figure 2. Mean ( $\pm \mathrm{SE}$ ) rates of trophallaxis (number of feedings $/ \mathrm{h}$ ) in relation to larval volume and larval food deprivation (food-deprived larvae: $N=44$; satiated larvae: $N=34$ ).

area: $t=-0 \cdot 12$; Ns; length: $t=0 \cdot 10$, NS; volume: $t=0.08$, NS). Larvae located atop the brood pile were antennated by workers at twice the rate as 
larvae located at the bottom $(t=2 \cdot 20, P<0.05$; $\bar{X} \pm \mathrm{SD}=471 \cdot 3 \pm 35 \cdot 0$ versus $275 \cdot 7 \pm 25 \cdot 2$ ).

\section{Rate of assessment}

As with the rate of contact, the rate of assessment (licking) was not influenced by larval fooddeprivation $(t=0.25$, Ns). Larval length, volume and surface area were equally good predictors $\left(r^{2}=0.65,0.64,0.69\right.$, respectively) of the rate at which larvae were licked (length: $t=2.22, P<0.05$; surface area: $t=2.28, P<0.05$; volume: $t=2.28$, $P<0.05$ ). The rate of assessment (like the rate of contact) was affected by larval location $(t=2 \cdot 24$, $P<0 \cdot 05$ ). Because worker-larva interactions were videotaped from above the brood chamber, the extension of the glossae coupled with each headbob was verified on less than half of the recorded licks. Therefore, results on the rate of licking should be considered preliminary.

\section{Rate of feeding versus rate of encounter}

Larvae were encountered $200-800$ times/h while being fed 2-50 times/h: more than an order of magnitude difference. The rate at which larvae were fed was independent of the rate at which larvae were antennated (regression: $r^{2}=0 \cdot 001, \mathrm{Ns}$ ) or licked (regression: $r^{2}=0 \cdot 04$, Ns) by workers.

\section{Temporal patterns of contact or trophallaxis}

The temporal patterns of contact or trophallaxis between workers and any given larva were generally unpredictable. Contacts were random over time for approximately $25 \%$ of the larvae, clustered for approximately $50 \%$ of the larvae and uniform for the remaining 25\% $(N=78)$. Long intervals between contacts $(>20 \mathrm{~s}$, creating the clustering effect) were caused most often $(64 \%)$ by workers blocking access to larvae during trophallaxis or while resting on the brood pile. Feedings were random over time for the majority of larvae $(96 \%)$. Feedings for the remaining $4 \%$ of larvae were clustered. Observing temporal patterns for longer periods (hours rather than minutes) may provide different results. Any negative effects from the temporal patterns of contact on the rate of larval feeding were probably swamped by the very high rates of contact.

Because the rates of trophallaxis were unaffected by three factors, (1) the rates of contact,

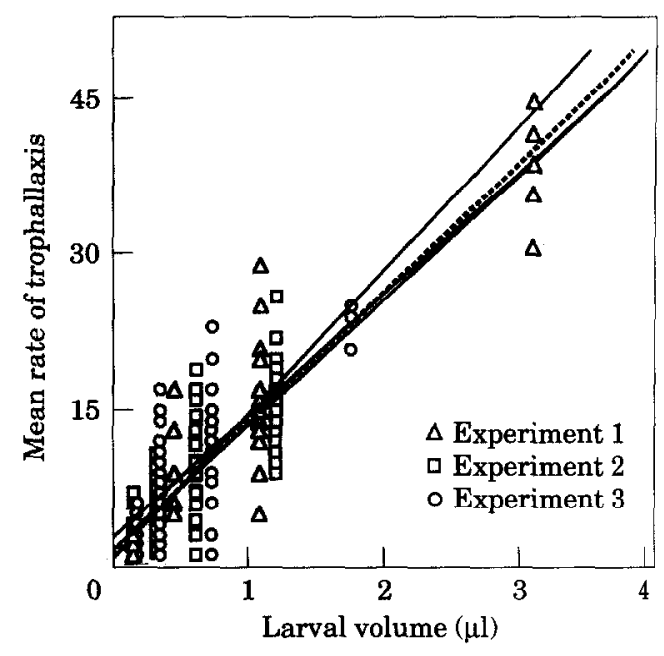

Figure 3. Rates of trophallaxis (number of feedings/h) in rclation to larval volume. Solid lines represent regres. sions for experiments 1,2 and 3, respectively ( $N=168$, 169 and 78, respectively). The dotted line is the mean: regression calculated by pooling experimental data.

(2) the rates of assessment, or (3) the location of larvae on the brood pile, these factors were not recorded in later experiments. Instead, subsequent experiments focused on resolving the effects of larval size and food-deprivation on the rate of larval feeding by workers.

\section{Experiments 2 and 3: Larval Size}

The effect of larval size on feeding rates was further tested in two experiments, one in which larvae of different sizes were combined and tested in the same experimental nest, and another in which larvac of different sizes were tested independently in separate nests. Regression slopes (size versus feeding rate) for the two experiments were nearly identical (experiment 2: rate $=1 \cdot 2+12 \cdot 2 X$; experiment 3: rate $=0 \cdot 4+14 \cdot 1 X ; t=0 \cdot 69, d f=336$, NS; Fig. 3), suggesting that food-deprived larvae were fed at rates characteristic of their size irrespective of the size of adjacent larvae. Because the regression slope for larval size from experiment 1 (rate $=2.4+11.9 X)$ was statistically similar to those from experiments 2 and $3\left(F_{2,335}=0.86\right.$. Ns), data were pooled and a single regression was determined (rate $=0 \cdot 96+12.8 X$; Fig. 3 ). The rate of trophallaxis increased approximately 13 feedings for every $\mu l$ increase in larval volume. 


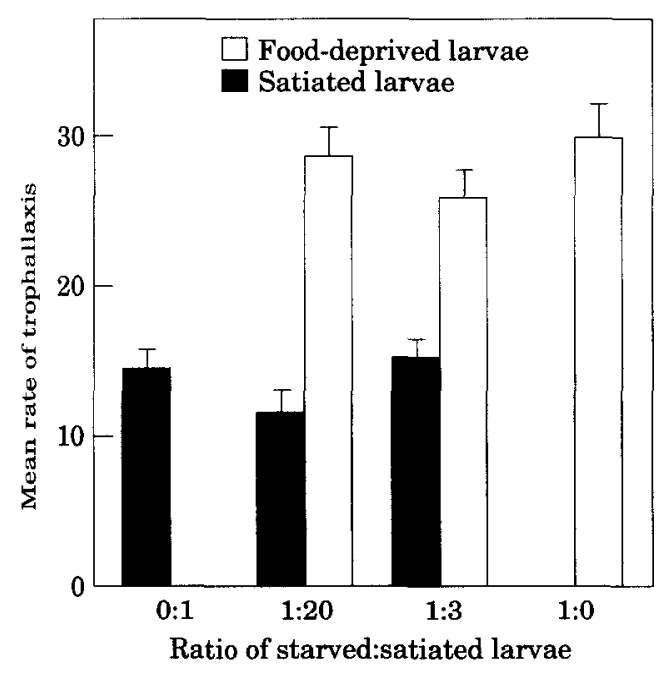

Figure 4. Mean ( $\pm \mathrm{SE}$ ) rates of trophallaxis (number of feedings $/ h$ ) to larvae in relation to the ratio of fooddeprived to satiated larvae within a brood pile. The difference in the feeding rate between food-deprived and satiated larvae persisted independent of the food deprivation level of surrounding larvae within the brood pile $(N=444)$.

\section{Experiment 4: Ratios of Satiated and Food-deprived Larvae}

Would workers find, assess and feed a few hungry larvae if most of the surrounding larvae were satiated? Food-deprived larvae were fed at characteristically high rates irrespective of the food-deprivation state of adjacent larvae $\left(F_{3,227}=2 \cdot 54\right.$, Ns; Fig. 4). Similarly, satiated larvae were fed at characteristically low rates irrespective of the food-deprivation state of adjacent larvae $\left(F_{3,207}=1 \cdot 40\right.$, NS $)$. Thus, workers responded to a specific larval hunger cue from individuals rather than to a blended cue from the brood pile.

\section{Experiment 5: Other Larval and Worker Food-deprivation Periods}

Worker food-deprivation had no effect on the rate of trophallaxis to larvae $(t=1 \cdot 68, d f=238$, NS). This negative result probably occurred because the difference in worker food-deprivation prior to executing the experiment was erased when food was introduced into the arena just before videotaping. Data from food-deprived workers were pooled for the analysis of larval food-deprivation.

Did shorter food-deprivation periods result in proportionately fewer feedings to larvae? Twelve

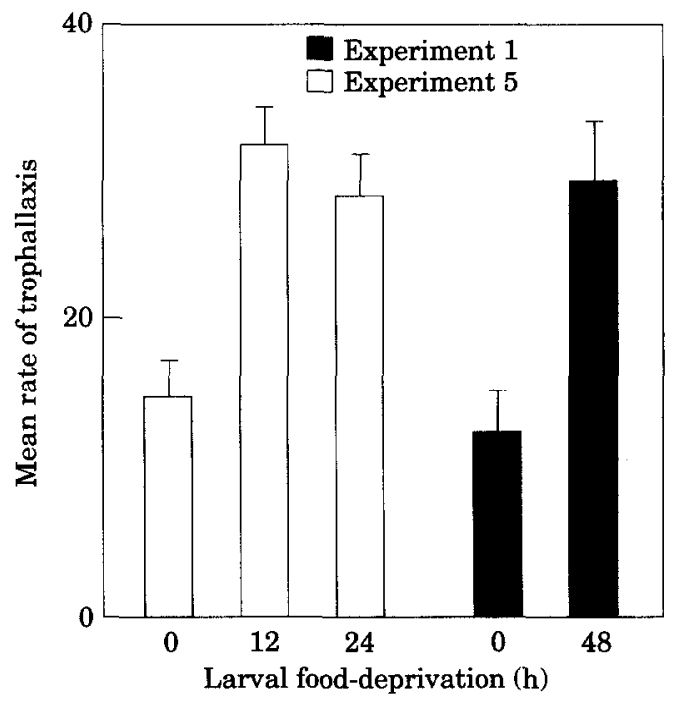

Figure 5. Mean ( $\pm \mathrm{SE}$ ) rates of trophallaxis (number of feedings $/ \mathrm{h}$ ) in relation to larval food-deprivation (experiment 1: $N=78$; experiment 5: $N=84$ ).

and 24-h food-deprived larvae were fed significantly more often than satiated larvae $(0 \mathrm{~h}$ versus $12 \mathrm{~h}: t=6.20, d f=160, P<0.01 ; 0 \mathrm{~h}$ versus $24 \mathrm{~h}$ : $t=4.94, d f=158, P<0.01$; Fig. 5). However, there was no significant difference in the rates of trophallaxis between the 12-h and 24-h larval groups $(t=1 \cdot 19, d f=120, \mathrm{Ns})$. These rates remained consistent regardless of the food-deprivation state of adjacent larvae from paired feeding treatments. Sated larvae were fed at the same low rate whether paired with $12-\mathrm{h}$ or $24-\mathrm{h}$ food-deprived larva $(t=-1.88, \quad d f=80$, Ns). Twelve-hour fooddeprived larvae were fed at the same high rate whether paired with 0 -h or $24-\mathrm{h}$ food-deprived larvae $(t=0.47, d f=80$, NS). Twenty-four hour food-deprived larvae were fed at the same high rate whether paired with 0 -h or 12-h fooddeprived larvae $(t=1 \cdot 4, d f=78, \mathrm{NS})$. The rates of trophallaxis for $12-\mathrm{h}$ and $24-\mathrm{h}$ food-deprived larval groups were nearly identical to the rate for a 48-h food-deprived group from experiment 1 (Fig. 5); this result suggested that larval fooddeprivation beyond $12 \mathrm{~h}$ had no detectable effect on larvae to which the workers could respond.

\section{Experiment 6: Larval Feeding during 12 Hours}

Throughout the 12-h observation period, worker coverage of the brood pile varied little 


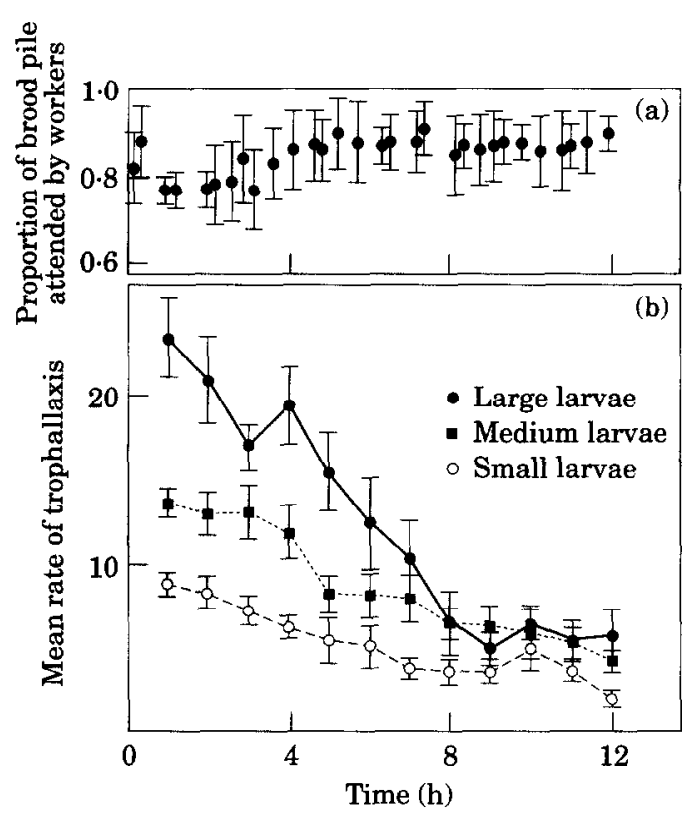

Figure 6. (a) Proportion ( $\bar{X} \pm \mathrm{SE}$ ) of the brood pile attended by workers through time (regression: proportion $=0.80+0.01 X, r^{2}=0 \cdot 43$ ). (b) Mean ( $\pm \mathrm{SE}$ ) trophallaxis rates (number of feedings/h) over time $(N=778)$.

from a mean $85 \%$ (Fig. 6a). In contrast, the rate of worker-to-larva trophallaxis declined as larvae became satiated during the first eight hours (large larvae regression, rate $=23 \cdot 8-2 \cdot 0 X, r^{2}=0 \cdot 45$; medium larvae regression, rate $=14.6-0.9 X$, $r^{2}=0.59 ;$ small larvae regression, rate $=9.0-0.55 X$, $r^{2}=0.42$; Fig. 6b). The observed decline in feeding was not a result of a decline in the number of workers attending larvae on the brood pile. The continuation of feeding at a reduced rate after $8 \mathrm{~h}$ suggested that, once larvae became satiated, workers maintained their sated condition. Regressions of the period from 8 to $12 \mathrm{~h}$ did not differ significantly from zero (large larvae, $t=-0 \cdot 15$, $d f=59$, Ns; medium larvae, $t=-1 \cdot 44, d f=77$, Ns; small larvae, $t=-0 \cdot 25, d f=83$, NS).

Large larvae were fed more than twice as often as small larvae throughout the $12 \mathrm{~h}\left(F_{2,5 s z}=49 \cdot 12\right.$, $P<0.0001$; Fig. 6b). Initially, large larvae were fed more than 1.5 times as often as medium larvae, but this difference became non-significant after $8 \mathrm{~h}$ $(t=0 \cdot 11, d f=102, \mathrm{Ns})$.

All larvae, regardless of size, had received $50 \%$ of their total number of feedings by $4 \mathrm{~h}$
$\left(F_{2,41}=0.47, \mathrm{Ns}\right)$ and $95 \%$ of their total number of feedings by $10 \mathrm{~h}\left(F_{2,41}=0 \cdot 40\right.$, NS). This finding suggested that larvae of all sizes were brought to satiation together.

\section{Experiment 7: Larval Orientation}

More larvae were oriented with their mouthparts up (55.2\%) than with their mouthparts down $(44.8 \%)$. The slightly higher percentage of larvae lying with their mouthparts up may be due to their curved shape. Larval orientation did not affect the rate of feeding to larvae $\left(F_{1.87}=0.55, \mathrm{Ns}\right)$. With one exception, larvae were so loosely piled that workers had easy access to mouthparts whether larvae were oriented with their mouthparts up or with them down. The exception, a larva with its mouthparts not only oriented down but also blocked by a larger larva's body, was not fed during the first $30 \mathrm{~min}$ of observation. Subsequently, a worker reoriented the larva such that its mouthparts were oriented up; it was then fed at a rate similar to other larvae. Larvae rarely remained in one orientation for more than $1 \mathrm{~h}$.

\section{DISCUSSION}

Although the allocation of food to larvae by workers appears haphazard, it is governed by the following rules operating at the level of the individual worker. (1) Each nurse worker patrols the brood pile constantly, such that every larva is encountered every few seconds by a worker; none is ever neglected. (2) Each nurse worker assesses larval hunger briefly with a quick sweep of the antennae, the maxillary palpi and possibly a quick lick with the glossae. (3) Having assessed a larva, each nurse worker makes only a binary feeding response (feed or do not feed). (4) The probability of a worker feeding a larva after assessment increases with larval size or hunger. Each larva attracts feedings at a rate regulated directly by its state of hunger and ultimately by its particular size. The net effect of these rules is that workers allocate food to larvae such that larvae are brought to satiation together; no larva is fed at the expense of another larva.

With behavioural complexity constrained by relatively few neurons in the central nervous system, the simplification of the worker response to one that is binary rather than graded allows a 
probabilistic control system at the individual worker level. The sum total of this simple response by many workers (a classic example of a seriesparallel behavioural sequence; Oster \& Wilson 1978) results in a highly reliable feeding system, turning a probability of being fed into a certainty; if one worker fails to feed a hungry larva, another will shortly succeed.

We speculate that, as a larva's cue weakens with satiation, the probability of stimulating workers to feed it diminishes; only the few workers with low response thresholds would continue to feed small or nearly satiated larvae. If this prediction is borne out by testing, then larval feeding is mechanistically similar to the recruitment of foragers to fond by trail pheromones (Wilson 1962, 1971). Both are cumulative responses of binary decisions mediated by the rate at which large numbers of individuals make these decisions. Just as recruitment is regulated by the probability that a food source will stimulate a worker to add an increment of pheromone to the trail, social feeding is regulated by the probability that the larval hunger cue will stimulate a worker to add an increment of food to the larva. Quantitative control resides at the group, not the individual level.

Although our experiments were not designed to characterize the larval hunger cue, it is likely to be chemical rather than behavioural or tactile. Of the 15000 feedings recorded from 1500 larvae (most of which had been food-deprived), only eight larvae were observed to rock their heads and move their mandibles in the rhythmic fashion described by O'Neal \& Markin (1973). Feeding never occurred during or immediately following this behaviour. Several lines of evidence suggest that the hunger cue is a non-volatile chemical, possibly a metabolic by-product. First, the larval hunger cue did not operate over a long distance as would an auditory cue; satiated larvae were contacted just as often as were food-deprived larvae. Second, ants tend brood in dark, underground chambers, eliminating visual cues. Third, worker chemoreceptors (the antennae, glossae and possibly the palps) were used to assess larval hunger. It is necessary that the cue operates over a short distance or upon contact, because a long-distance chemical or auditory cue from many closely spaced larvae would quickly merge into indistinguishability.

Several data outliers from experiment 5 (the 12-h experiment) hint that the strength of the hunger cue might be regulated by larval attributes in addition to size or level of food deprivation. Three larvae were fed a disproportionately large number of times for their size. The rate of feeding was so high (over 100/h) that workers sometimes displaced other workers engaged in feeding a larva by nudging away the other's mouthparts to initiate their own feeding of that larva. These 'feeding frenzies' were sustained for over $2 \mathrm{~h}$, suggesting that some larvae have a much stronger hunger cue than their same-sized siblings. Identifying the source and cause of this difference in hunger cue strength may provide insight into the source and cause of worker polymorphism and caste determination.

Experiment 5 revealed two important characteristics of the larval feeding system. First, feedings lasted about $8 \mathrm{~h}$ before larvae were brought to satiation. Second, larval satiation was maintained by infrequent but regular feedings. This regular feeding pattern after satiation is in contrast to the bout feeding pattern of most solitary insects (Tschinkel 1985), wherein long periods of fasting occur between meals. To maintain a regular flow of food to larvae, the relatively large reserve workers may act as temporary storehouses (Vinson 1986), damping fluctuations in the flow of food from the foraging territory outside the nest to the larvae deep inside the nest.

One curious aspect of the fire ant feeding system was the high rate of larval contact by workers (hundreds per h) compared with the rate of trophallaxis (tens per h). Each larva was contacted from 50000 to 120000 times by workers during its lifetime as a larva. Honey bee nurses reportedly visited larval cells 10000 times (Lineburg 1924a, cited in Ribbands 1953) reinforcing the idea that eusocial insect workers bestow 'lavish care' on larvae (Hölldobler \& Wilson 1990). An investigation of the worker's role in larval feeding may provide insight into the cause of this high contact:feeding ratio.

Our findings suggest that fire ants tend their brood differently than do other ant species. Leptothorax acervorum larvae suffered negative effects of random temporal patterns of contact by workers (Hatcher et al. 1992), but the high rate of larval contact by fire ant workers probably swamped any possible negative effects of contact pattern. Large $M$. rubra larvae were sometimes favoured at the expense (in weight gain) of small larvae (Brian 1957), but fire ant larvae were fed at 
a rate characteristic of their size regardless of the size of adjacent larvae. In $M$. rubra, larval piling was hypothesized to interfere with optimal larval growth (Brian 1956), but in fire ants, larval piling did not interfere with the rate of larval feeding, probably because larvae at the bottom of the brood pile were still encountered frequently enough for workers to assess and respond to individual larval hunger. Lastly, M. rubra, larvae are assessed by a labour-intensive, trial-and-error method ('test-servicing': LeMasne 1953) during which larvae are licked or offered food to determine feeding readiness (Brian 1956). By contrast, the duration of larval assessment by fire ant workers was brief and reliable. Workers assessed larvae with quick sweeps of the antennae sometimes followed by single licks with the glossae; larvae always ingested food when workers offered it. Perhaps this brevity of assessment is an adaptation associated with large colonies. A comparative study of larval hunger assessment mechanisms within a genus offering a wide range of mature colony sizes would address this hypothesis.

The high repeatability of our larval feeding results within and between experiments was in contrast to similar investigations by Brian (1957), Brian \& Abbott (1977), and Sorensen et al. (1985; see Introduction). Their variable results may have resulted from too small sample sizes. During our own pilot studies employing fewer than 100 workers and larvae, worker response was sometimes sluggish or non-existent, resulting in erratic feeding rates within and between treatments. Because larval feeding at the individual level is a probabilistic event, large numbers of workers are required for a precise execution of larval feeding. Employing thousands of ants greatly improved the reliability of our experimental results. Still, generalizing our results beyond our relatively small laboratory-reared fire ant colonies must await quantification of larval feeding in larger field colonies because behavioural differences may result from different rearing environments (Wood \& Tschinkel 1981; Porter \& Tschinkel 1985a, b).

\section{ACKNOWLEDGMENTS}

We thank Deborah Burr and Duane Meeter from the Statistical Consulting Center for advice on statistical methods and Michael Sloderbeck for creating our computerized event recorder. We thank Donald McInnes, Peter Wainwright, Meredith West, Ann Thistle, Patti Loesche and two anonymous referees for suggested improvements to the manuscript. This is paper no. 26 of the Fire Ant Research Team. We gratefully acknowledge the support of the National Science Foundation grant BSR-8920710.

\section{REFERENCES}

Abbott, A. 1978. Nutrient dynamics of ants. In: Production Ecology of Ants and Termites (Ed. by M. V. Brian), pp. 233-244. Cambridge: Cambridge University Press.

Banks, W. A., Lofgren, C. S., Jouvenez, D. P., Stringer, C. E., Bishop, P. M., Williams, D. F., Wojcik, D. P.\& Glancey, B. M. 1981. Techniques for rearing, collecting and handling imported fire ants. USDA SEA Agric. Technol. sth Ser., 21, 1-9.

Brian, M. V. 1956. Studies of cast differentiation in Myrmica rubra La: controlled larval nutrition. Insectes soc., 3, 369-394.

Brian, M. V. 1957. Food distribution and larval size in cultures of the ant Myrmica rubra L. Physiol. comp. Oecol, 4, 329-345

Brian, M. V. 1986. The importance of daylength and queens for larval care by young workers of the ant. Myrmica rubra L. Physiol. Entomol., 11, 239-249.

Brian, M. V. \& Abbott, A. 1977. The control of food flow in a society of the ant Myrmica rubra L. Anim. Behav., 25, 1047-1055.

Byrkit, D. R. 1980. Elements of Statistics. New York D. Van Nostrand.

Carlin, N. F. 1988. Species, kin and other forms of recognition in the brood discrimination behavior of ants. In: Advances in Myrmecology (Ed. by J. C. Trager), pp. 267-295. Leiden: E. J. Brill.

Deneurbourg, J. L., Gooss, S., Franks, N., SendovaFranks, A., Detrain, C. \& Chretien L. 1991. The dynamics of collective sorting: robot-like ants and ant-like robots. In: Simulations of Animal Behavior: from Animals to Animals (Ed. by J. A. Meyer \& E. 0. Wilson), pp. 356-365. Cambridge, Massachusetts: Cambridge University Press.

Franks, N. R. \& Sendova-Franks, A. B. 1992. Brood sorting by ants: distributing the workload over the work-surface. Behav. Ecol. Sociobiol, 30, 109-123.

Hatcher, M. J., Tofts, C. \& Franks, N. R. 1992. Mutual exclusion as a mechanism for information exchange within ant nests. Naturwissenschaften, 79, 32-34.

Hodgeman, C. D., Weast, R. D. \& Selby, S. M. 1956. Handbook of Chemistry and Physics. Cleveland: Chemical Rubber.

Hölldobler, B. 1978. Ethological aspects of chemical communication in ants. Adv. Study Behav., 8, 75-115.

Hölldobler, B. \& Wilson, E. O. 1990. The Ants. Cambridge, Massachusetts: Harvard Press.

Howard, D. F. \& Tschinkel, W. R. 1980. The effect of colony size and starvation on food flow in the fire ant 
Solenopsis invicta (Hymenoptera: Formicidae). Behav. Ecol. Sociobiol, 7, 293-300.

Howard, D. F. \& Tschinkel, W. R. 1981a. Food preference in colonies of the fire ant Solenopsis invicta (1). Insectes soc., 28, 217-222.

Howard, D. F. \& Tschinkel, W. R. 1981b. The flow of food in colonies of the fire ant, Solenopsis invicta: a multifactorial study. Physiol. Entomol., 6, 297-306.

Huang, Z. \& Otis, E. W. 1991. Inspection and feeding of larvae by worker honey bees (Hymenoptera: Apidae): effect of starvation and food quantity. $J$. Insect Behav., 4, 305-317.

Hunt, J. H. 1991. Nourishment and the evolution of the social Vespidae. In: The Social Biology of Wasps (Ed by K. G. Ross \& R. W. Matthews), pp. 426 450 . Ithaca, New York: Comstock.

Le Masne, G. 1953. Observations sur les relations entre le couvain et les adultes chez les fourmis. Annls Sci. nat., 15, 1-56.

Lenoir A. 1981. Brood retrieving in the ant, Lasius niger L. Sociobiology, 6, 153-178.

Markin, G. P. 1970. Food distribution within laboratory colonies of the Argentine ant, Iridomyrmex humilis (Mayr). Insectes soc., 17, 127-158.

Montgomery, D. C. \& Peck, E. A. 1982. Introduction to Linear Regression Analysis. New York: John Wiley.

0'Neal, J. \& Markin, G. P. 1973. Brood nutrition and parental relationships of the imported fire ant Solenopsis invicta. J. Ga entomol. Soc., 8, 294-303.

Oster G. F. \& Wilson, E. O. 1978. Caste and ecology in the social insects. Monogr. Pop. Biol., No. 12.

Pendral, B. A. \& Plowright, R. C. 1981. Larval feeding by adult bumblebee workers (Hymenoptera: Apidae). Behav. Ecol. Sociobiol., 8, 71-76.

Petralia, R. S. \& Vinson, S. B. 1978. Feeding in the larvae of the imported fire ant Solenopsis invicta: behavior and morphological adaptations. Ann. entomol. Soc. Am., 71, 643-648. "

Petralia, R. S. \& Vinson, S. B. 1979. Comparative anatomy of the ventral region of ant larvae, and its relation to feeding behavior. Psyche, 86, 375-394.

Porter, S. D. \& Tschinkel, W. R. 1985a. Fire ant polymorphism (Hymenoptera: Formicidae): factors affecting worker size. Ann. entomol. Soc. Am., 78, 381-386.

Porter, S. D. \& Tschinkel, W. R. 1985b. Fire ant polymorphism: the ergonomics of brood production. Behav. Ecol. Sociobiol., 16, 323-336.

Ribbands, C. R. 1953. The Behaviour and Social Life of Honeybees. London: Bee Research Association.

Ryan, B. F., Joiner, B. L. \& Ryan, T. A., Jr. 1985. Minitab Handbook. Boston: PWS-KENT.

Sorensen, A. A., Busch, T. M. \& Vinson, S. B. 1985. Control of food influx by temporal subcastes in the fire ant Solenopsis invicta. Behav. Ecol. Sociobiol., 17, 191-198.

Sorensen, A. A., Kamas, R. \& Vinson, S. B. 1980. The biological half-life and distribution of 125 iodine and radioidinated protein in the imported fire ant, Solenopsis invicta Buren (1). Entomol. exp. appl., 247-258.

Sorensen, A. A., Kamas, F. \& Vinson, S. B. 1983. The influence of oral secretions from larvae on levels of proteinases in colony members of Solensopsis invicta Buren (Hymenoptera: Formicidae). J. Insect Physiol., 29, 163-168.

Sorensen, A. A. \& Vinson, S. B. 1981. Quantitative food distribution studies within labor colonies of the imported fire ant, Solenopsis invicta Buren (1). Insectes soc., 28, 129-160.

Sutcliff, G. H. \& Plowright, R. C. 1988. The effects of food supply on adult size in the bumble bee Bombus terricola Kirby (Hymbenoptera: Apidae) Can. Entomol., 120, 1051-1058.

Tennant, L. E. \& Porter, S. D. 1991. Comparison of diets of two fire ant species (Hymenoptera: Formicidae): solid and liquid components. J. entomol. Sci., 26, 450-465.

Tschinkel, W. R. 1985. Behavior and physiology. In: Fundamentals of Insect Physiology (Ed. by M. S. Blum), pp. 391-435. New York: John Wiley.

Vander Meer, R. K. \& Morel, L. 1988. Brood pheromones in ants. In: Advances in Myrmecology (Ed. by J. C. Trager), pp. 491-513. Leiden: E. J. Brill.

Vinson, S. B. 1986. The physiology of the imported fire ants: basic gaps in our understanding. In: Fire Ants and Leaf-cutter Ants: Biology and Management (Ed. by C. S. Lofgren \& R. K. Vander Meer), pp. 289--301. Boulder, Colorado: Westview Press.

Wallis, D. I. 1962. The relationship between hunger, activity and worker function in an ant colony. Proc. zool. Soc. Lond., 139, 589-605.

Wheeler, D. E. 1986. Developmental and physiological determinants of caste in social Hymenoptera: evolutionary implications. Am. Nat., 128, 13-34.

Wheeler, D. E. 1990. The developmental basis of worker polymorphism in fire ants. $J$. Insect Physiol., 36, 315-322.

Wheeler, D. E. 1994. Nourishment in ants: patterns in individuals and societies. In: Nourishment and Evolution in Insect Societies (Ed. by J. Hunt \& C. Nalepa), pp. 245-278. Boulder, Colorado: Westview Press.

Wheeler, M. W. 1918. A study of some ant larvae, with a consideration of the origin and meaning of the social habit among insects. Proc Am. phil. Soc, 57, 293339.

Wilson, E. O. 1962. Chemical communication among workers of the fire ant Solenopsis saevissima (FR. Smith): II. An information analysis of the odour trail. Anim. Behav., 10, 148-158.

Wilson, E. O. 1971. The Insect Societies. Cambridge, Massachusetts: Harvard Press.

Wood, L. A. \& Tschinkel, W. R. 1981. Quantifying modification of worker size variation in the fire ant Solenopsis invicta. Insectes sac, 28, 117-128.

Zar, J. H. 1974. Biostatistical Analysis. Englewood Cliffs, New Jersey: Prentice-Hall. 